\title{
Contemporary Technologies to Improve the Quality of Education When Training Teachers
}

\author{
Alfiya Sibgatullina ${ }^{1}$ \\ ${ }^{1}$ The Elabuga institute of Kazan Federal University, Elabuga, the Republic of Tatarstan, Russia \\ Correspondence: Alfiya Sibgatullin, The Elabuga institute of Kazan Federal University, Elabuga, the Republic of \\ Tatarstan, Russia. E-mail: a.sibgatullina@bk.ru
}

Received: October 31, 2014 Accepted: November 28, 2014 Online Published: February 25, 2015

doi:10.5539/ies.v8n3p167 URL: http://dx.doi.org/10.5539/ies.v8n3p167

\begin{abstract}
The article considers contemporary technologies to improve the quality of teachers' education (as exemplified by the training of foreign language teachers). The author presents analysis of the "quality of education" concept, proposes and analyzes the criteria for assessing the quality of education of future foreign language teachers. Application of below described methods and techniques in the training of future teachers (informational and communicational technologies, remote technologies, e-learning, activity-based learning, and others) should contribute, in author's opinion, to the formation of the teacher's professional competence.
\end{abstract}

Keywords: quality of education, subjective-methodological competence of the teacher, psychological and pedagogical competence, social competence, self-learning, innovation activity, remote technologies, e-learning

\section{Introduction}

The problem of improving the quality of education when training teachers is caused by several factors:

- The contradiction between the increasing requirements for the teacher training process and the result, and a decrease of the profession prestige in today's socio-economic situation;

- the contradiction between the growing demands for professional training of a teacher, as a carrier of culture, and the current status of future teachers education level, resulting from a lack of clear understanding by society of the education objectives;

- The lack of consistency between the levels of teacher's training in higher education institutions and the requirements of the school, school administration and parents to the teacher.

- In this article, we review the evaluation of the higher vocational education quality of a teacher (as exemplified by the training of a foreign language teacher), as well as contemporary technologies to improve the quality of education.

The issues on improving the quality of teacher's training, as well as harmonizing the system of teacher's education with the standards of teacher's professional work and the Federal State Educational Standard (hereinafter FSES) are raised also in currently developed "Concept to support the development of pedagogical education".

The amendments to the law "Concerning Education", which came into force on January 1st, 2013, show that issues on education quality are becoming increasingly important. In this law, the quality of education is defined as "a comprehensive description of educational activities and the training of a trainee, expressing the degree of their compliance with federal state educational standard, educational standards, the federal government requirements and (or) the needs of the natural person or legal entity, in whose interests the educational activities are exercised, including the extent, to which the expected results of the educational program are attained (Zeer, 2006, pp. 13-14).

In addition, "The concept of modernization of Russian education for the period up to 2010" emphasizes that the result of today's high-quality education concludes not only in knowledge and skills, but also in formed educational expertise and core competencies of a person. As a result of theoretical apprehension and analysis of the investigated concepts interpretations, pertained to Baydenko (2004), Zimnyay (2004), Selevko (2004), Hutorskoy (2002) and others, we describe expertise as personal characteristic of a student, his potential, based on 
acquired knowledge, his life and educational experiences, values and propensities. Competence is a narrower concept, which is characterized by us as a requirement for a student's educational background, specified in advance; a synthesis of knowledge, skills and abilities, enabling him to successfully carry out activities, role and function (Sibgatullina, 2009, p. 11).

As is obvious, the quality of education is a comprehensive indicator reflecting the following:

- Objectives and training outcomes;

- The educational process participants satisfaction by offered educational services;

- A certain level of knowledge, skills and experiences, expertise and competencies of the individual identified with respect to the requirements applicable to this individual.

The National Doctrine of Education in the Russian Federation for the period up to 2025 (National Doctrine of Education in the RF, 2000) defines the following expected results in the field of education quality enhancement: the establishment of a democratic education system, ensuring the necessary conditions for a complete quality education at all levels; individualization of the educational process through the diversity of types and forms of educational institutions and educational programs that take into account the interests and abilities of the individual; competitive level of education in terms of both the educational programs content and the quality of educational services.

\section{Methodology}

According to the Federal State Educational Standard (FSES) in the field of "Pedagogical Education" (FSES of Higher Education, 2010), a graduate, who studied in a certain field, should possess the following competencies: general cultural, general professional and professional competencies. The criteria for the training quality of foreign language teachers are subject-methodological competence, psychological and pedagogical competence, and readiness of teachers to implement innovative educational activities.

Further we consider how each of these criteria is evaluated. The subject-methodological competence of the teacher means the body of knowledge in the subject taught, the level of awareness in contemporary research on subject taught, knowledge of teaching methods, as well as the ability to choose or develop the technology or methodology, necessary for particular educational process (Shchetinina, 2008). Final state certification and the results of student's educational and on-the-job training, in our opinion, should be a source of evaluating the education quality received by a graduate. On the state assessment for foreign language proficiency a student is evaluated in terms of acquiring core subjects of professional cycle of basic and optional part of the curriculum, his general cultural and professional competence. Effectiveness of passing by graduate on-the-job training at school shows his awareness towards social significance of his future profession and the made choice, the possession of the motivation for the implementation of professional activities. It is very important after passing the teacher on-the-job training to conduct interviews with students about the teacher role in today's society. Exactly after the on-the-job training of students we can designate so-called "crisis of professional choice revision and correction", when some of students experience frustration in the teaching profession and start to search other options for future employment (Zeer, 2006).

Considering the psychological and pedagogical competence of a future teacher, we focus on its main components that include the psychological literacy (i.e. knowledge, which in FSES is called general professional knowledge); psychological skills as a teacher's ability to use his knowledge in teaching activities, as well as professionally important personal qualities, whose presence is inseparable from the teaching process. How to assess the psychological and pedagogical competence of a student who is going to become a teacher? Again, it can be done directly during his professional activities. None of result-rating examinations can show the student's ability to respond to complex psychological and pedagogical situation.

Innovative activity is targeted to the improvement of scientific and pedagogical, educational, organizational, legal, economic and financial, human, and logistical support of the education system (Education Law of the Russian Federation, 2013, p. 38). As is rightly pointed out by Pavlova, innovation in pedagogic activity is not a new phenomenon, given that each stage of the development of pedagogical history and thought is specified by its innovations (Pavlova, 2009, p. 9). Criteria for assessing the readiness of foreign language teacher to implement innovative teaching activities, as already noted, can be teacher's personal achievements, presentation of his innovation activity, which is reflected in the academic achievements of his schoolchildren (academic performance, the quality of knowledge, participation in Olympiads, etc.).

As we can see, each of the above criteria of teacher's training quality is reflected in the forms of competence of the young (future) teacher. And a competence includes a plurality of theoretical knowledge, as well as practical 
skills and abilities, enabling one to successfully perform the work of a teacher. Perhaps, the content of the pedagogical on-the-job training programs and teaching technologies require changes in order to ensure implementation of the new professional standard for teachers and new standards of school education (according to the "Concept to support the development of teacher education").

Unfortunately, teachers of pedagogical universities often have to deal with the fact that some students, perfectly possessing core subject (in this case a foreign language), turn out to be poor teachers, when starting school practices. This is unformed methodical competence of future teacher. Methodological competence is a "tool" for the successful conduct of the lesson. Sometimes schoolchildren, who are willing to learn, hunger for knowledge and spend much time on learning process, though do not achieve significant results. The reason lies in the fact that they cannot learn, that is, the schoolchild must be taught not only a foreign language, but learning strategies of studied subject, which can be conditionally divided into the following:

- Reading patterns (the study of reading patterns, ability to pick out key words, marking text and its analysis, etc.);

- Teaching schoolchildren writing, performing written work (requirements to the written works of various genres, the structure of the written work, the correction of written work, evaluation and self-evaluation);

- Learning memorization techniques (the problem of remembering and forgetting what was learned, mnemonics and review);

- Training in epitomize (the ability to hear, highlight the core and to analyze);

- Training in oral work in the classroom (work types and forms, evaluation criteria, accounting for psychological features of a child in the process of an individual or pair work, etc.);

- Ability to work with presentations (benefits of visual presentation, training in oral and written presentations);

- Teaching schoolchildren creative thinking during the learning process 21.22.

What are the existing education quality enhancement technologies that could have a significant impact to improve the training of the future teachers, in forming their subject-methodological competence?

Firstly, a system of knowledge in an educational institution needs to be focused on the training of foreign language teachers and must have an appropriate structure. Curriculum, based on the corresponding profile of FSES, is primarily responsible for what the student should learn (academic disciplines and to what extent), whereas the quality of mastering each piece of information of the curriculum depends on a teacher. Here one can use pedagogical components for the enhancement of educational process, which include the optimal selection of educational information, providing schoolchildren educational material for self-study, the effective use of individual means of training, the use of various forms and methods of problem-based learning, etc. The teacher does not only teach students the learning methods of a particular subject, but demonstrates of doing lessons by his own example, showing how to work as a foreign language teacher. The method of "Learning through training» (Lernen durch Lehren) was first developed in the early 80's of the last century by Dr. Jean-Paul Martin, Professor of the Eichstatt University, didactic, teacher and methodologist (Wikipedia, Learning through training, 2013). Jean-Paul Martin gives the following definition of this method: "If a student develops training material independently, and then presents it to his classmates and wonders, whether his information is perceived and understood by other students, if he develops suitable exercises for mastering the topic, then all these actions form a method of "Learning through training» (Witwer, 1996, p. 317). Despite the fact that described method is intended for the use by student, this technique is very effective when training teachers, as this is kind of practice, where the student learns to be a teacher. This method also helps passive students to better realize their potential, because its use can improve their self-confidence, allows them to feel as a teacher yet not in the school classroom, but in a more comfortable student community. This method makes it possible to integrate imagination, creativity and diversity to the lesson.

Today the free education technique is poorly understood and has many interpretations. This issue was developed by the German educators G. Bryugelmann, F. Peschel, J. Ramseger, and V. Vallrabenshteyn. They highlight the following differences between the free (open) learning and other forms of educational process. Here core of the learning methodology is based on the individual disciplinary and interdisciplinary abilities and interests of each child, which determine the structure and organization of the educational process, as well as the independent development by the students of extra-curricular activities that go beyond the academic process (Peschel, 2002, p. 36). The "open learning" concept (offener Unterricht) means "openness" of substantive, methodological and organizational aspects of learning and aims at providing the most free creative space, both for teachers and for 
students.

The above considered procedures of the activity-based learning are well established in the teaching of foreign languages. They are suitable for the education of the future foreign languages teachers in terms of their self-sufficiency, as well as the formation of their communicative and methodical competence (Sibgatullina, 2013, p. 19).

In addition, the teacher is one of the most important socio-oriented professions, therefore there is no doubt concerning the importance of social competence maturity of future teachers. At that, social competence is considered as:

- The ability to function in society, to know the problems of society, to understand the mechanism of its activity;

- Social activity and implementation of socially oriented projects;

- The ability of a person to adapt socially in society, taking the rules, regulations and social life laws; and at the same time, the ability to realize himself as a unique personality, to carry out a conscious choice, to form value system, acceptable to himself and society;

- The ability of a person to function in society, to take responsibility, to participate in joint decision-making in the operation and development of the social and democratic institutions (Kolycheva, 2003, pp. 27-28).

During the development of the social competence of future teachers the most important, in our view, is the formation of the following abilities of the student:

- The ability for empathy, i.e. Understand and empathy at other people's emotions;

- Learning the role-playing distance (ability to comply with accepted norms and expectations in a given society);

- Teamwork ability (to listen to the opinions of others, the ability to "try on" different roles);

- The ability to maintain independence in the disputed issues and conflicts;

- The ability to correctly assess the experience (own and others) and be open to use the experience of others in their work.

For the formation of students' social competence one should use the active learning technology. This involves an organization of the educational process, at which non-participation in the cognitive process is impossible. The development of empathy in the students, as future teachers, must be made via the use of pedagogical situations, teaching assignments, and purposeful design of humanitarian pedagogical environment. The use of literary texts during the classes and discussion of the issues raised in the text play a special role in the development of empathy.

In our view, students' teamwork ability can be successfully formed using project technology. Interactivity of project technology contributes to:

- The formation and development communication skills, as well as emotional contacts between students (the ability to live in an interactive environment and understanding, what a dialogue is and why it is needed);

- The formation and development of analytical skills and responsible attitude to students' own actions;

- The formation and development of organizational planning skills (the ability to predict and forecast own future) (Osipova, 2012, p. 101).

The so called method of "Six Thinking Hats", developed by Edward de Bono, an expert in the field of creative thinking, is another exiting technique for formation of the social competence of the future teachers. Six thinking hats technique allows us to develop mental flexibility, creativity, perfectly helps to overcome writer's block, helps to make a right decision and to more accurately relate one's thought way with set goals and challenges. It is particularly well suited for the evaluation of unusual and innovative ideas, where it is important to take into account any view and consider the situation from different perspectives.

Self-study (self-education) is process that must accompany people of a particular profession over the whole their life; this certainly is true to teacher. In the training of future teachers especially important is, in our opinion, the formation of the following competencies and qualities:

- Taking responsibility for learning outcomes;

- Creating own learning style and strategy; 
- Availability of motivation for learning, self-development, commitment to innovation in education;

- Possession of time-management technology and enhancing its efficient use.

Today, self-learning techniques have substantially advanced on the basis of modern information technologies. Distance learning system is based on predominantly independent acquisition of knowledge in the required amount and quality, and at the same time involves the use of a wide range of both traditional and new visual information technologies. Information technologies in distance learning can be used in very different forms, such as a case-technology, sending the studied material over computer networks (through e-learning systems, in particular), etc. With ever increasing frequency, today we can hear the opinion that the current distance learning courses displace traditional teacher and that there comes a time for online learning. The use of distance learning in foreign language study has its own advantages and disadvantages. It is believed that the use of the Internet will lead in the future to a retreat from the traditional forms of full-time education in favor of the remote e-learning. As is known, the main purpose of teaching foreign languages at the present stage is the formation of communicative competence, which in turn, provides for the development of intercultural communication skills. Internet provides a unique opportunity to get acquainted with the culture of the target language country, providing a cross-cultural interaction, allowing one to listen and communicate with native speakers, i.e. Internet creates a natural language environment.

However, despite the unique didactic properties of computer telecommunication network, we cannot disagree with Dmitrieva $(1998$, p. 317) that the preparation of such e-courses practically does not take into account the specificity of the methodology, which reflects the psychological and pedagogical conditions, inherent in distance learning. This specificity includes:

- The demand for more careful and detailed planning of the trained student's activity;

- The demand for high-efficiency feedback; trained students should be confident in the correctness of their solutions while progressing from ignorance to knowledge;

- The availability of motivation as the most important element of any distance learning course; for this it is important to use a variety of techniques and tools;

- The modular structuring of the e-course to ensure the trainee to be able to clearly aware of his advance from module to module, to be able to select any module at his discretion or at the discretion of the mastering teacher.

Contemporary teaching aids are an important part of the educational process. In its role as an integral part of the educational process, they have an impact on other components as well, such as the methods, forms, content and learning objectives. Each academic subject needs special training aids. When learning a foreign language, today widespread popularity has acquired multimedia language lab (MLL). Studies of teachers and trainers allow identifying the following advantages of using MLL:

- MLL allows increasing the time of oral practice for each student that would enhance the efficiency of the educational process, when forming required communicative competence; it can create the conditions for individual and differentiated training of students (accounting for student abilities, his pace of work and the ways of perceiving information during the sessions);

- MLL enhances learning motivation. Study in the language laboratory provides interactivity and visibility, which, with proper guidance of the teacher, makes learning an exciting work. This is particularly important at the stage of forgetting foreign words (high school, non-initial training). In order not to forget the words, one need to use them in different ways, namely, pronouncing them, reading, listening, applying in the various contexts, etc.

- MLL allows one to work extensively on the lexical, grammatical and phonetic aspects of language. Here language lab is especially useful because it allows the simultaneous demonstration of audio, video and text files that removes a number of language learning difficulties. At that, the MLL allows simultaneous conduct of individual, pair and group work.

The numerous linguistic databases, multimedia, Internet courses, virtual tours over the countries, etc. make it possible to significantly enrich and expand linguistic and cultural practices of students.

A podcast is another innovative multimedia tool useful when teaching foreign languages. Podcast is an audio and video material often in mp3 format, which are available to students and teachers through the Internet. They are constantly updated and can be downloaded for free from certain web sites. Podcast promotes the aural understanding of foreign language and provides training of spoken language based on the proposed tasks. As a 
rule, the text duration is not greater than four minutes. The main advantage of the podcast is its authenticity, as well as formation of creative multimedia competence of a student (Makarevich I.G., 2012, p.40).

Also, when speaking of the contemporary technologies of teaching foreign languages, we cannot ignore e-learning. We cannot say that it is most advantageous in training teachers. On the contrary, when training the student to work as a teacher, the main emphasis should be focused on the formation of his personality through the direct communication with educator. Though, learning through the Internet, and in particular, a modular object oriented Moodle e-learning, introduced recently, has quite good capabilities:

- To provide the student with basic and additional training materials that are necessary and sufficient for the study of a particular discipline;

- To provide consultancy to the student in order to make effective use of materials provided for the study of the discipline;

- To provide clear monitoring, recording and documenting of progress in solving the training tasks, posed by teacher and trainees' self-control for the correct execution of tasks.

In addition, the Moodle system enables to provide multivariate presentation of information, interactive learning, repetition of the material under study, structuring of the content and its modularity, the creation of a constitutively active reference system, self-checking of learning activities, alignment of individual educational paths, privacy in training and compliance with the principles of successful learning (Andreev A.V., 2008, p.8).

And the last thing we would like to note, when considering the issue of improving the quality of teacher training. One of the major issues of this training is the interaction between the university and the school, which can be considered in the following areas:

- A teaching and methodological interaction, which includes the preparation and testing of textbooks, teaching aids for schoolchildren and teachers working at school; management of training activities for core subjects; communication of school teachers with university teachers for the purpose of consultations and exchange of experience.

- Scientific and methodical work, which contains the following forms: holding joint roundtable discussions on the most important issues of joint activities, organization of methodology workshops at the chairs of higher education institutions with the involvement of school teachers and etc.; reviewing research and project work of schoolchildren by university teachers; involvement of school teachers in scientific and practical conferences held at the universities; conduct of subject olympiads and competitions among secondary school students on the basis of universities; organization of university-based elective courses and scientific circles for schoolchildren; providing methodological support by university teachers in developing curricula of secondary educational institutions in vocation-related subjects; using the university facilities to improve the knowledge of schoolchildren, the involvement of university teachers in training of schoolchildren for regional and all-russian olympiads and contests.

- Vocational guidance work: conducting "doors open days" at the university; meetings with teachers, students and their parents in order to provide information about the university admission rules and the conditions of education. In turn, a school should become a platform for scientific research. This is especially significant for the pedagogic universities, since the school is the basis for on-the-job training of the students, receiving a teacher diploma, to acquire and improve their teaching skills.

\section{Results}

Thus, taking current FSES of the higher education as a base, quality criteria to evaluate foreign language teacher's training were based on subject-methodological competence, psychological and pedagogical competence, as well as the readiness of teacher to implement innovative educational activities. Each of the designated criteria is reflected in the manifestations of teacher's competencies, to which we assigned his methodological competence, social competence and self-education competence. In our opinion, to form these competencies, one should use both educational process enhancement technology (project technologies, information technologies, etc.), and the possibility of interaction between the school and higher educational institution.

\section{Discussion}

The issue of enhancing the quality of education of the future teacher is raised today not only within the framework of a regular school (in teachers' meetings, methodological seminars, etc.), but also in the system of higher pedagogical education. Various grants and contests for teachers are targeted to this aim, whose primary 
objective is the identification and dissemination of effective teaching experience, the development of creative potential and enhancement of professional qualification of teachers, as well as the development of innovative and experimental activities of teaching staff. These are the following competitions:

- Open International remote competition of pedagogical projects "Golden Pelican-2014";

- Open International competition of pedagogical ideas "Pedagogical Space-2014";

- Open All-Russian competition of innovative methodological developments "Innovation-2014";

- "Our new teacher", a grant of the Ministry of Education of the Republic of Tatarstan, etc.

Pedagogical higher education institutions, in turn, work according to the networking programs on interaction between schools and the higher education institutions.

\section{Conclusion}

Thus, we have come to the conclusion that a professional teacher's training is a comprehensive challenge. Its implementation requires from the teacher application of both contemporary (innovative) and the classical (traditional) methods and technologies. The considered technologies and techniques are not a full comprehensive coverage of all the approaches towards improvement of the education and training quality of the future teachers. We have analyzed only a part of them, which, in our opinion, is very important, when assessing the quality of education.

\section{References}

Andreev, A. V., Andreeva, S. V., \& Dotsenko, I. B. (2008). The practice of e-learning using Moodle. Taganrog: South Federal University Press.

Baydenko, V. I. (2004). Competences: Towards competence-based approach. Lecture conducted from Research center on problems of quality training, Moscow.

Dmitrieva, E. I. (1998). The major methodological problem of distance learning of foreign languages through the Internet computer telecommunication network. Foreign Languages at School, 1, 6-11.

Hutorskoy, A. V. (2002). Key competencies and educational standards. Eidos Internet Magazine. Retrieved from http://www.eidos.ru/journal/2002/0423.htm

Kolycheva, Z. I. (2003). Social competence of the teacher in the light of the education modernization. Proceedings of the Herzen Russian State Pedagogical University, 6, 26-35.

Makarevich, I. G. (2012). Podcast in learning German. Foreign Languages at School, 5, 36-40.

Martin, J. P. (2013). Learning through training. Retrieved July 16, 2013, from http://ru.wikipedia.org/?oldid=57056953

Osipova, S. I., \& Okuneva, V. S. (2012). Project activities to form students' teamwork ability. Siberian Pedagogical Journal, 5, 96-101.

Pavlova, E. P. (2009). Pedagogical conditions for development of innovative activity in primary school teachers during the education modernization process (as exemplified by the Republic of Sakha (Yakutia)) (Ph.D. thesis, Yakutsk).

Peschel, F. (2002). Open education. Part II (p. 36). Hohengehren.

Selevko, G. K. (2004). Competences and their classification. Public Education, 4, 138-143.

Shchetinina, N. A. (2008). Improvement of subject-methodological competence of the teacher. Retrieved from http://www.festival.1september.ru/articles/537987

Sibgatullina, A. A. (2009). Formation of culturological competence of the future foreign language teacher for a national school (Ph.D. thesis, Moscow).

Sibgatullina, A. A., \& Samsonova E. V. (2013). The activity approach to building research competences among prospective teachers. Proceedings of the International Congress on Interdisciplinary Behavior and Social Science, Indonesia, 510-512.

Wittwer, A. (1996). Action-oriented teaching of foreign languages (French) with the method of learning by teaching. Education and school life, 51(3), 317-324.

Zeer, E. F. (2008). Psychological features of the professional development crises. Retrieved from http://www.psyhological.ucoz.ua/publ/56-2-2 
Zimnyaya, I. A. (2004). Key competences as effectually-targeted competency-based approach to education. Lecture conducted from Research center on problems of quality training, Moscow.

\section{Copyrights}

Copyright for this article is retained by the author(s), with first publication rights granted to the journal.

This is an open-access article distributed under the terms and conditions of the Creative Commons Attribution license (http://creativecommons.org/licenses/by/3.0/). 